\title{
Philosophiques
}

\section{Émile Chrétien, Le Québec philosophique, Montréal, McGraw-Hill, 1991, pages}

\section{André Vidricaire}

Volume 20, numéro 2, automne 1993

Perspectives sur la phénoménologie et l'intentionnalité

URI : https://id.erudit.org/iderudit/027246ar

DOI : https://doi.org/10.7202/027246ar

Aller au sommaire du numéro

Éditeur(s)

Société de philosophie du Québec

ISSN

0316-2923 (imprimé)

1492-1391 (numérique)

Découvrir la revue

Citer ce compte rendu

Vidricaire, A. (1993). Compte rendu de [Émile Chrétien, Le Québec philosophique, Montréal, McGraw-Hill, 1991, pages]. Philosophiques, 20(2),

519-521. https://doi.org/10.7202/027246ar d'utilisation que vous pouvez consulter en ligne.

https://apropos.erudit.org/fr/usagers/politique-dutilisation/ 


\section{Émile Chrétien, Le Québec philosophique, Montréal, McGraw-Hill, 1991, pages \\ par André Vidricaire}

Emile Chrétien a fait paraître un manuel qui a pour but d'initier à la philosophie par son histoire et plus particulièrement par l'histoire de la réflexion québécoise en philosophie. Sauf erreur, c'est la première fois qu'un manuel d'enseignement de la philosophie affiche et affirme son enracinement dans le territoire québécois. Cette innovation remplie de risques comporte des faiblesses qu'tl faut attribuer, à mon avis, à la carence de nos travaux sur la pensée québécoise. Aussi, les remarques que je vais formuler voudraient s'inscrire dans une expérimentation franche de ce manuel dans un cours de CEGEP pour en permettre un approfondissement et une consolidation.

Ce manuel divisé en trois parties traite I) de l'objet de la philosophie (l'homme, la société et la connaissance) ; 2) de l'histoire des philosophies qui tant en Occident qu'au Québec se rattachent à l'idéalisme ou au matérialisme; 3) pour se terminer par l'étude de la pensée philosophique de Marx, Sartre et François Hertel (1905-1985). C'est dans ce contexte que Chrétien soutient qu'au Québec l'histoire de la pratique philosophique aurait été « entre 1665 et 1967 » une philosophie « éclectique », « presque exclusivement » thomiste, si on excepte six auteurs qui appartiendraient au courant matérialiste. Ainsi dans ce manuel, 'histoire de la réflexion québécoise en philosophie ne connaît qu'une seule direction. Il n'y a pas d'expériences divergentes, sauf pour de rares exceptions. Sous la poussée et à cause de l'omniprésence d'un système clérical, cette histoire n'est faite que d'agents, mais jamais de sujets autonomes, d'auteurs, d'écrivains qui auraient poursuivi et affirmé une démarche personnelle de réflexion. Il n'y a qu'une ligne d'autorité qui a imposé son propre système de pensée et de légitimation à tous ceux qui se sont adonnés à la réflexion philosophique. Ce pouvoir a sécrété son propre savoir. D'un mot, il n'y a jamais eu 
d'expériences autonomes de la pensée qui, consciente de la présence du pouvoir, aurait cherché à s'en sortir, à affirmer son autonomie propre et à penser autrement. Ce n'est pas tout. Au cœur même de ce système religieux - car c'est bien de cela qu'il s'agit - il n'y a pas de tensions, de polémiques, de divergences soit de direction et de moyens, de formulations et de compréhensions ou encore, de définitions et d'explications. De même qu'il n'existe pas de sujets - ou si peu! - qui critiquent le système, de même il n'existe pas, non plus, de sujets qui, tout en se déclarant appartenir à telle position philosophique, diffèrent d'opinions et mènent une réflexion singulière. D'un mot, notre histoire de la pensée est toute tracée par une autorité omnipotente qui non seulement a suscité son propre système de pensée mais encore a imposé à ses agents ce qu'ils devraient penser.

Aussi, cette histoire « locale » de la pensée se trouve évidemment complètement fermée à toute influence. Dans un passé lointain, le système clérical nous a mis les mots dans la bouche et depuis ce temps-là - soit de « I665 à 1967 » nous n'avons fait que sacraliser ces mots en les répétant, nous fermant de siècle en siècle, de génération en génération, aux apports des réflexions européennes et américaines. Bref, une culture entièrement verrouillée dont la clé a été entre les mains de l'autorité. Autant dire que la réflexion a été muette tant le bâillon était efficace.

Il serait extrêmement urgent de se demander d'où nous vient cette vision de nos expériences de réflexion en philosophie, quels intérêts nous entretenons à maintenir cette vision, ce qu'elle vient expliquer et justifier pour notre temps présent. Il serait très important de se demander à partir de quoi et à partir de qui nous en sommes venus à penser notre histoire de la philosophie dans ces termes? D'un mot, à quoi nous en prenons-nous pour reconstituer une histoire qui s'avère une faillite monumentale? Comme on le voit, l'enjeu est d'interroger l'histoire de cette histoire, les postulats, les croyances, les traditions, les non-dits, les passions, les luttes, les impasses qui nous habitent nous-mêmes.

A mon avis, il est possible de proposer une autre reconstitution de cette histoire de notre philosophie où nous verrions i) que toujours notre pensée est contemporaine de ce qui se passe en Europe, 2) qu'elle comporte des débats et des conflits ; 3 ) qu'elle est affaire d'interprétations idiosyncratiques et communes à ce qui se fait ailleurs au même moment ; 4) qu'elle se produit dans un rapport culture dominante / culture périphérique. D'un mot, pour moi, à côté des agents, il y a des sujets, des auteurs, des écrivains, des philosophes qui vont braver le système. Pour moi, il n'y a pas de direction préétablie, mais plutôt des effets de forces de la concurrence, des catastrophes. La bataille des Plaines d'Abraham n'a jamais connu de vainqueur intellectuel. Il s'est toujours trouvé des sujets autonomes qui ont trouvé la philosophie digne d'être conquise, et $c e$, en dépit des échecs du passé, des erreurs de parcours et de la terrible autorité qui se prétend dépositaire de la Vérité-vérité. En résumé, l'expérience du spiritualisme chez les philosophes des Régimes français et anglais, puis après I840 et 1879 , est multiple, disparate et pleine d'erreurs, selon le point de vue de L.A. Pâquet ! L'intérêt est d'expliquer les formes que cette tradition de pensée a prise au cours de cette histoire, comment chaque auteur a utilisé cette tradition, selon quelle conjoncture et dans quels buts. Selon moi, ce questionnement va 
nécessairement conduire à se demander s'il existe, au Québec, une tradition de réflexion matérialiste? A quand remonte-t-elle ? Dans quelle circonstance s'est-elle développée ? Quels sont les auteurs continentaux qui ont servi de référence ? Quels usages les philosophes locaux ont fait du matérialisme? Dans quels buts ? Or, à ce propos, je puis faire erreur, mais je ne crois pas que se développent au Québec, avant le début du XXe siècle, une seule œuvre individuelle « matérialiste », encore moins un courant ou une tradition matérialiste. Certes, il y a des anticléricaux, parmi lesquels s'excluent Parent et Pelletier, mais ils sont tous déistes. Même I.J. Papineau qui affirmait « ne pas croire dans la Révélation [...] voyait venir la mort avec un calme absolu, persuadé que Dieu ne le punirait pas pour n'avoir pas cru à des dogmes qu'en son âme et conscience il croyait injurieux á sa bonté et à sa justice » (propos de Dessaulles dans Roger Lemoine : Napoléon Bourassa, Ottawa, 1974, p. gol. Evidemment, seules des recherches monographiques minutieuses permettraient de confirmer ou non mon hypothèse. Mais en supposant qu'elle s'avère vraie, il serait opportun d'expliquer une telle absence (!), et ses effets sur la liberté de pensée et ce, non pas dans le but de 'se taper sur la tête', mais pour faire apparaitre comment les auteurs-écrivains-philosophes-sujets ont maintenu la quête d'une réflexion libre en philosophie dans leurs modes de lecture et d'écriture.

\section{Département de philosophie}

Université du Québec à Montréal 